\title{
DESCORNA DE BOVINOS UTILIZANDO GRAMPOS DE METAL NA DERMORRAFIA
}

\author{
USE OF METAL CLAMPS FOR SKIN SUTURE AFTER CATTLE DEHORNING
}

\author{
Maria Clorinda Soares Fioravanti ${ }^{1}$ Luiz Antônio Franco Silva ${ }^{1}$ Maria Auxiliadora Leão $^{2}$ \\ Raquel Soares Juliano ${ }^{2}$ Duvaldo Eurides $^{3}$ Claúdia Dueno Alves ${ }^{4}$
}

\section{RESUMO}

\begin{abstract}
Os grampos de metal foram empregados na dermorrafia de 50 vacas mestiças (Zebu/Holandês) de peso variado, com idade entre 18 e 60 meses após serem submetidas à descorna plástica. Os animais foram operados em diferentes propriedades rurais do Estado de Goiás, durante os anos de 1995 e 1996 e avaliados durante o pós-operatório. Quatro animais apresentaram exsudação serosa local, dois dias após a cirurgia; um animal desenvolveu sinusite unilateral e, em dois outros, houve deiscência da ferida. A técnica utilizada reduziu o tempo de cirurgia, facilitou a divulsão da pele e produziu hemostasia satisfatória. A aplicação dos grampos foi rápida e fácil, e a cicatrização satisfatória.
\end{abstract}

Palavras-chave: descorna, sutura, grampos de metal, bovino.

\section{SUMMARY}

Metal clamps were used in dermal suture of fifty crossbred cattle, of various weight, ranging from 1.5 to 5 years of age; after esthetic dehorning. The animals were operated on differents farms from Goiás State, Brazil, during 1995 and 1996 and evaluated after surgery. Four animals showed serous exudation two days after surgery. One animal had unilateral sinusitis and in other three there were wound dehiscence. The technique proposed was fast; skin divulsion was easier, there was a good hemostasy and cicatrization was esthetic. Metal suture is fast and easily applied.

Key words: dehorning, suture, metal clamps.

\section{INTRODUÇÃO}

A descorna cosmética do gado proporciona uma aparência estética e uniforme, principal- mente, em animais de exposição; além de facilitar o manejo do rebanho e exigir menor espaço no cocho para a alimentação (VILLAGRAN \& MATAMOROS, 1969). As lacerações e perfurações de pele ocorrem com menor frequiência, aumentando a qualidade do couro. Os mesmos autores recomendaram a tranqüilização do animal para a realização da cirurgia. A técnica operatória compreendeu incisões cutâneas frontais, ventrais e circulares, exteriorizando a base do corno para a posterior amputação da apófise óssea. A sutura da pele foi realizada com pontos simples isolados. ALEXANDER (1971) optou pela incisão circular da pele e sutura com pontos simples separados.

LAZZERI et al.(1975) utilizaram, após tranqüilização e anestesia local, duas incisões cutâneas semicirculares, amputando os cornos com uma serra de lâmina e fechando a pele, com fio de algodão, por meio de sutura tipo Donatti. A utilização de anestesia local, sem tranqüilização prévia e a sutura da pele com fio de algodão 0000 , com ponto simples interrompido foi recomendada por SILVEIRA (1985).

A descorna deve ser realizada em animais com menos de um ano de idade; pois nos mais velhos pode não haver pele suficiente para proceder a dermorrafia. A operação foi feita por TURNER \& McILWRAIGHT (1985) com o animal em posição quadrupedal e a incisão de pele praticada na base do corno, sendo seguida por hemostasia por meio de torção da artéria cornual e dermorrafia com fio inabsorvível em ponto contínuo simples.

\footnotetext{
${ }^{1}$ Médico Veterinário, Professor do Departamento de Medicina Veterinária da Escola de Veterinária da Universidade Federal de Goiás (EV/UFG), Campus Samambaia, Goiânia, Goiás, CP 131, 74001-970. Autor para correspondência.

${ }^{2}$ Médico Veterinário, Aluno de Pós-graduação da EV/UFG.

${ }^{3}$ Médico Veterinário, Professor do Departamento de Medicina Animal da Universidade Federal de Uberlândia, Minas Gerais.

${ }^{4}$ Aluno de Graduação da EV/UFG. 
Os fios inabsorvíveis são os mais utilizados na sutura da pele, principalmente, o fio de algodão; entretanto este possui a desvantagem de ser capilar e possibilitar reações corporais do tipo "corpo estranho" (LAZZERI, 1977). Os materiais metálicos têm como vantagem a facilidade de esterilização, a rápida aplicação e podem ser utilizados em casos onde há infecção, além de produzir cicatrização linear e rápida (ANNIS, 1973; STEINCHEN \& RAVITCH, 1973). Diante da diversidade de opções de materiais disponíveis para sutura cutânea, o cirurgião deve estar familiarizado com suas vantagens e desvantagens, para fazer a melhor escolha (FIORAVANTI $\boldsymbol{e t}$ al., 1996a).

Este trabalho teve como objetivo descrever uma técnica cirúrgica de descorna em bovinos, onde a dermorrafia foi realizada com grampos de arame galvanizado.

\section{MATERIAL E MÉTODOS}

Foram utilizadas 50 vacas mestiças (Bos taurus/Bos indicus), com peso variado e idade entre 18 e 60 meses, provenientes de diferentes propriedades rurais do Estado de Goiás e Hospital Veterinário da EV/UFG, atendidos em 1995 e 1996. Os instrumentais cirúrgicos utilizados foram uma serra de arco, cabo de bisturi e lâmina $\mathrm{n}^{\mathrm{0}} 24$, pinça hemostática de Crille, pinça de Backaus, tesoura cirúrgica curva ponta romba, alicate ${ }^{a}$ curvo para anéis de retenção e alicate ${ }^{\mathrm{b}}$ curvo para tapeçaria, modificados segundo proposto por FIORAVANTI et al. (1996 a); grampos de metal galvanizado ${ }^{c}$ esterilizados. Foi respeitado o jejum prévio de 12 horas e, para contenção química, foi administrado cloridrato de xilazina $^{\mathrm{d}}$, na dose de 0,1 a $0,2 \mathrm{mg} / \mathrm{kg}$, por via intramuscular (ANDREI, 1995).

$\mathrm{O}$ animal teve os membros pélvicos atados com cordas, na região metatársica e foi colocado em decúbito esternal. A cabeça foi contida com um cabresto, de modo que a ponta da corda quando amarrada no membro, na altura do jarrete e tracionada, trazia a cabeça para o lado e para trás, apoiandoa sobre o costado do animal. A porção do cabresto que ficava sobre o chanfro do animal foi colocada na boca (figura 1). Após a tricotomia e antissepsia com iodophor $^{\mathrm{e}}$, fez-se anestesia local infiltrativa do nervo cornual e aurículo-palpebral, conforme o proposto por LAZZERI et al. (1975) e SILVEIRA (1985). Realizou-se uma incisão semicircular, na base do processo córneo, iniciando na crista do occipital e finalizando na crista do frontal, na posição da fossa temporal. A pele foi dissecada e a apófise córnea foi serrada em $3 / 4$ de seu diâmetro, sendo fraturada caudalmente. Utilizando o chifre como alavanca, a pele

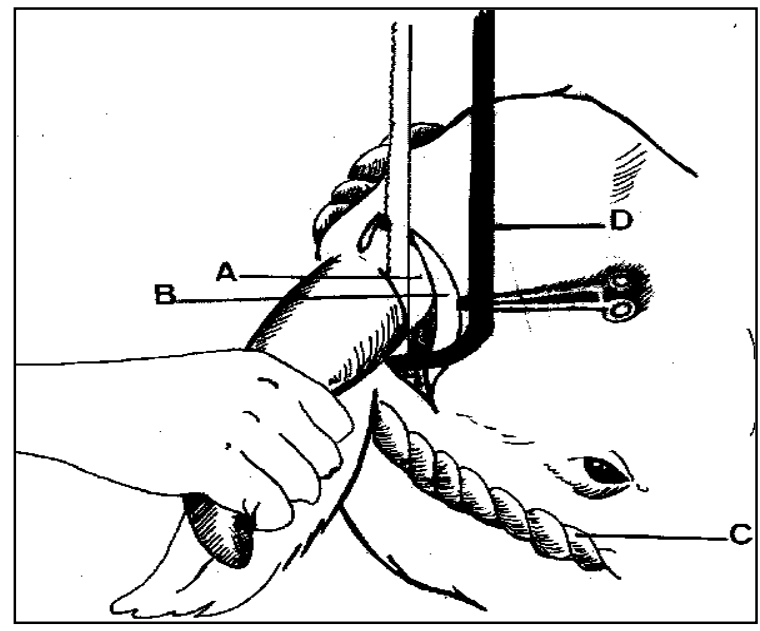

Figura 1 - Técnica para descorna em bovinos - A: base do corno; B: incisão de pele na porção anterior e divulsão; C: cabresto; D: serra de arco para descorna.

da porção posterior foi descolada (SILVEIRA, 1985). Posteriormente, a incisão caudal da pele foi feita, próxima à base do corno, tomando cuidado para não atingir os vasos. A hemostasia foi feita por torção, utilizando o próprio chifre antes de arrancálo totalmente. Antes da síntese da pele, foram retirados os coágulos e esquírolas ósseas. Com o auxílio de duas pinças Backaus, as bordas da ferida cirúrgica foram aproximadas e os grampos aplicados, lado a lado, com o alicate de tapeçaria, até o fechamento completo da ferida (figura 2).

No pós-operatório, foi realizada antibioticoterapia com penicilina $G$ benzatina, penicilina $G$ procaína, penicilina $\mathrm{G}$ potássica e diclofenaco de sódio ${ }^{\mathrm{f}}$, na dose de $10.000 \mathrm{UI} / \mathrm{kg}$, por via intramuscular (ANDREI, 1995), a cada 48 horas, perfazendo três aplicações. O curativo local foi realizado diariamente, com óxido de zinco, óleo de fígado de cação, cloranfenicol levógiro sintético, sulfaguanidina e hexaclorociclohexano ${ }^{g}$, durante 20 dias. Os grampos foram retirados com alicate para anéis de retenção aos 18 dias e foi recomendado que os animais operados permanecessem separados do rebanho, até completar a cicatrização.

\section{RESULTADOS}

A tranqüilização e anestesia empregadas produziram adequada analgesia do animal, possibilitando a realização da cirurgia com segurança. A contenção química facilitou o posicionamento do paciente em decúbito esternal que, por sua vez, demonstrou-se adequado ao tipo de intervenção cirúrgica realizada. A utilização do cabresto, tracionando a cabeça do animal sobre o seu costado, proporcio- 


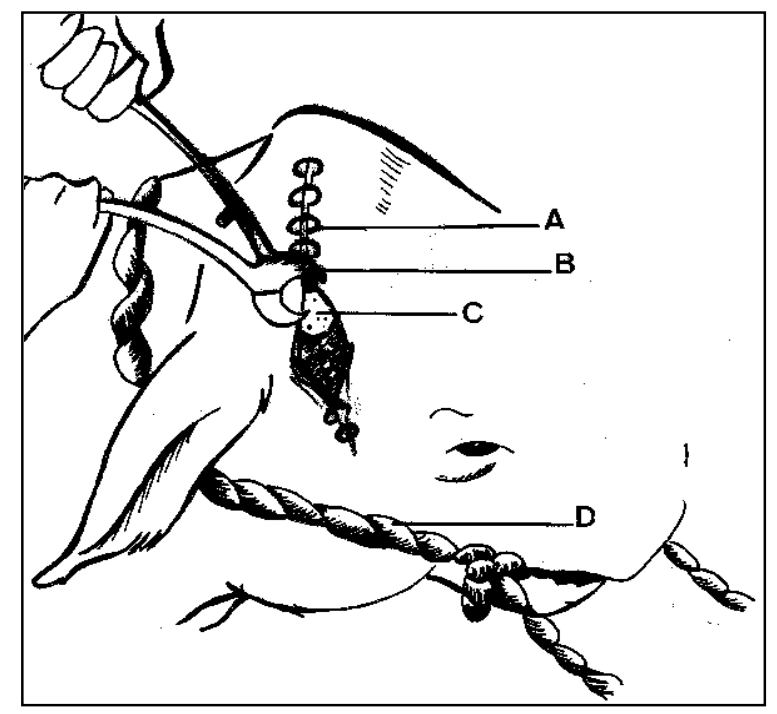

Figura 2 - Técnica de dermorrafia em bovinos submetidos à descorna - A: grampo de metal; B: alicate para aplicação dos grampos; C: coto do corno; D: cabresto.

nou maior conforto para o cirurgião e evitou a mudança de posição do animal, durante a cirurgia. A colocação de parte do cabresto na boca facilitou a respiração e permitiu o escoamento do excesso de saliva.

A técnica de hemostasia utilizada não apresentou resultado adequado somente em oito animais, que precisaram ter os vasos pinçados e ligados com fios. A retirada dos cornos começou sempre pelo lado que estava apoiado no costado do animal, o que facilitou a exposição do campo operatório pelo auxiliar. Quatro animais apresentaram exsudação serosa, dois dias após a cirurgia; e um animal apresentou sinusite unilateral após 21 dias, sendo tratado segundo protocolo proposto por FIORAVANTI et al. (1996b). Em dois animais, que apresentaram deiscência parcial da ferida, após a queda de alguns grampos, a cicatrização completa aconteceu após 30 dias; necessitando de curativos diários. A aplicação dos grampos foi rápida e fácil, a cicatrização após 18 dias foi satisfatória e a formação de edema subcutâneo foi discreta.

\section{DISCUSSÃO}

SILVEIRA (1985) dispensa a utilização de tranqüilizantes no pré-operatório; porém, neste trabalho, considerou-se que a inquietude dos bovinos e a contenção em decúbito esternal, sem a contenção química, poderiam oferecer perigo ao cirurgião e ao animal, além de dificultar a execução da cirurgia. Sendo assim, optou-se pelo método sugerido por
LAZZERI $\boldsymbol{e t}$ al. (1975), associando a tranqüilização à anestesia local.

A contenção mecânica, com cordas e cabresto, em decúbito esternal, foi considerada mais confortável e segura que a contenção em decúbito lateral, proposta por VILLAGRAN \& MATAMOROS (1969). A contenção em bretes, mantendo o animal em estação (TURNER \& McILWRAIGHT, 1985), não foi utilizada devido ao temperamento agressivo dos animais operados.

A tricotomia foi importante pois delimitou, de maneira uniforme, o local da amputação; para tanto, consideraram-se a raça e a conformação da cabeça, de modo que o resultado final não descaracterizou o animal. Outro fator importante que deve ser considerado é o sexo do animal.

A retirada dos cornos iniciando sempre pelo lado que está apoiado no costado do animal facilita a exposição do campo operatório pelo auxiliar. A situação inversa pode concentrar o ponto de apoio na orelha do paciente, aumentando a tensão da sutura e possibilitando a ocorrência de deiscência da ferida. A manobra cirúrgica de serrar o chifre e depois fraturá-lo, utilizando-o como alavanca para o descolamento da pele (SILVEIRA, 1985), realizada no presente trabalho, reduziu o tempo cirúrgico e facilitou a divulsão da pele.

O exsudado seroso, presente nos quatro animais, foi considerado normal para este tipo de cirurgia (FIORAVANTI et al., 1996b) e foi atribuído a presença de sangue nos seios frontais, decorrente da hemorragia que ocorre, invariavelmente, durante o transoperatório. A sinusite pode ser explicada pela queda dos grampos, seguida da deiscência da ferida; esta complicação é comum e foi citada por vários autores (ROSENBERGER,1988; JUBB et al., 1990 e JEFFREY \& WILLIAM, 1992).

A queda dos grampos pode ser resultado de erro na aplicação ou na conduta pós-operatória; principalmente nos casos onde não foi seguida a recomendação de isolamento dos animais operados; podendo, nestas situações, ter havido brigas. A recomendação de isolamento, apesar de ser considerada importante, não foi mencionada na literatura consultada.

A retirada de coágulos e esquírolas ósseas antes da síntese foi importante pois a cicatrização pode ser retardada quando esquírolas ósseas não são removidas (KIHURANI et al., 1989). Há necessidade de condutas higiênicas, pré e transoperatórias, para minimizar os riscos de infecção local, além da transmissão de outras enfermidades como a leucose bovina ou a brucelose (DIGIACOMO et al.,1987 e LASSAUZET et al., 1990).

O tipo de material de sutura utilizado está diretamente correlacionado com o grau de penetra- 
ção de bactérias (BENNETT, 1988). Como os grampos não perfuram a pele, a penetração de patógenos é menor, resultando em menos complicações pósoperatórias (ANNIS,1973, FIORAVANTI et al., 1996a).

O grau de traumatismo tecidual, o tempo operatório, o material de sutura, o uso de vasoconstrictores e a presença de coágulos ou "espaço morto" são fatores que interferem no reparo das feridas e no risco de infecção (CLARCK, 1980; JOHNSTON, 1981; NORTHWAY, 1983). O menor tempo gasto na cirurgia é fato de grande importância na obtenção de melhores resultados (CHAMPAULD et al., 1977; BELLENGER,1982). Estes fatores foram igualmente considerados no presente trabalho.

\section{CONCLUSÃO}

A contenção em decúbito esternal é satisfatória, imobiliza o animal de maneira confortável e segura para o cirurgião e o paciente. A tricotomia é um parâmetro importante de visualização estética nas descornas cirúrgicas. As modificaçõs na técnica convencional de descorna reduziram o tempo de cirurgia, facilitaram a divulsão da pele e produziram hemostasia satisfatória. A sutura com grampos metálicos galvanizados apresenta, como principais vantagens, a facilidade de esterilização dos grampos, a rápida aplicação e a cicatrização adequada da pele.

\section{FONTES DE AQUISIÇÃO}

${ }^{\text {a }}$ Ind. e Com. CORNETA $S$ a

${ }^{b}$ Alicate curvo Krause IMK 1840 - Ind. Mec. Krause Ltda.

${ }^{c}$ Grampos de tapeçaria para alicates Krause - Ind. Mec. Krause Ltda.

${ }^{\mathrm{d}}$ Dorcipec - Vallé Nordeste S.A.

e Biocid - Laboratórios Pfizer Ltda.

Pencivet - Laboratório Silva Araújo Roussel S.A.

${ }^{g}$ Ungüento Vallé - Vallé Nordeste S.A.

\section{REFERÊNCIAS BIBLIOGRÁFICAS}

ALEXANDER, A. Técnica quirurgica em animales. 2. ed México: Interamericana, 1971. 313 p.

ANDREI, E. Compêndio veterinário. 28. ed. São Paulo: Andrei, 1995. $749 \mathrm{p}$.

ANNIS, D.A. Sterile "use-once" clip applicator for skin closure. Br J Surg, v. 60, n. 9, p. 686-688, 1973

BELLENGER,C.R. Sutures. Part II, The use of sutures alternative methods of closure, Comp Cont Educ Pract Vet, v. 4, n. 7, p. 587-602, 1982

BENNETT, R.G. Selection of wound closure materials, J Am Acad Dermatol, v. 18, n. 4, p. 619-637, 1988
CHAMPAULD, G., GUILLEMING, G., PATAT, J.L. Les sutures mécaniques en médicine vetérinaire. Rec Med Vet, v. 153, n. 9, p. 551-560, 1977.

CLARCK, C.H. Use of antibiotics in wounds. Modern Vet Pract, v. 61, n. 4, p. 307-312, 1980.

DIGIACOMO, R.F., HOPKINS, S.G., DARLINGTON, R.L. Control of bovine leukosis virus in a dairy herd by a change in dehorning. Can J Vet Res, v. 51, p. 542-544, 1987.

FIORAVANTI, M.C.S., SILVA, L.A .F., BERNIS, W.O., $\boldsymbol{e}$ t al. Aspectos macroscópicos da dermorrafia de bovinos com grampos de metal galvanizados e fio de algodão. Arq Bras Med Vet Zoot, v. 48, n. 4, p. 425-434, 1996a.

FIORAVANTI, M.C.S., SILVA, L.A F., MOREIRA, P.C., $\boldsymbol{e}$ t al. Ácido metacresolsulfonico associado a nitrofurazona $\mathrm{e}$ enrofloxacina no tratamento de sinusite em bovinos. Vet Not, v. 2 , n. 1 , p. $31-36,1996$ b.

JEFFREY, L.W., WILLIAM, C.R. Chronic frontal sinusits in dairy cattle : 12 cases (1978-1979). J Am Vet Med Assoc, v. 201, n. 2, p. 326-328, 1992.

JOHNSTON, D.E. Skin and subcutaneous tissue. In: BOJRAB, M.J., Pathophysiology in small animal surgery. Philadelphia: Lea \& Febiger, 1981. p. 405-420.

JUBB, K.U.F., KENNEDY, P.C., PALMER, N. Patologia de los animales domésticos. Montevidéo: Hemisfério Sur, 1990, v. $2,653 \mathrm{p}$.

KIHURANI, D.O, MBIUKI, S.M.; NGATIA, T.A. Healing of dehorning wounds, Br Vet J, n. 145, p. 580-585, 1989.

LASSAUZET, M.L.G., THURMOND, M.C., JOHNSOS, W.O. et al. Effect of brucellosis vacination and dehorning on transmission of bovine leukemia virus in heifers on a California Dairy. Can J Vet Res, n. 54, p. 184-189, 1990.

LAZZERI, L., CARNEIRO, M.I., MASSONE, F., $\boldsymbol{e}$ t al. Descornamento plástico em bovinos. Anais Esc Agron Vet UFG, n. 1, p. 90-94, 1975.

LAZZERI, L. Fases fundamentais da técnica cirúrgica. São Paulo: Varela, 1977. 190 p.

NORTHWAY, R.B. Wound suturing. J Am Vet Med Assoc, v. 182, n. 4, p. 352-355, 1983.

ROSENBERGER,G. Enfermidades de los bovinos. Montevideo: Hemisfério Sur, 1988. v. 1, 577 p.

SILVEIRA, J.M. Novo método de descorna em bovino adulto Belo Horizonte, 1985. 28 p., Tese (Mestrado em Medicina Veterinária) -. Escola de Veterinária da UFMG, 1985.

STEINCHEN, L., RAVITCH, M.M. Mechanical sutures in surgery. Br J Surg, v. 66, n. 3, p. 191-197, 1973.

TURNER, A.S., McILWRAIGHT, C.W. Técnicas cirúrgicas em animais de grande porte. São Paulo: Roca, 1985. 341 p.

VILLAGRAN, E., MATAMOROS, R. Cosmetic dehorning. Rev Fac Med Vet Zootec, v. 2, n. 4, p. 119-121, 1969. 